Cadernos de

ESTUDOS LINGǘísTICOS - (54.1), Campinas, Jan./Jun. 2012

\title{
AFASIA E INFÂNCIA: REGISTRO DO (IN)ESQUECÍVEL
}

\author{
MARIA IRMA HADLER COUDRY* \\ SONIA SELLIN BORDIN**
}

\section{RESUMO}

Esse texto aproxima afásicos, que deixam de exercer a língua, de crianças com dificuldades em sua entrada na língua escrita. Tal reflexão se faz com base em práticas com a linguagem envolvendo fala, leitura e escrita; e na teorização atual desenvolvida pela Neurolinguística Discursiva, sobretudo à luz de Jackson, Freud e Jakobson.

Palavras-chave: Neurolinguística Discursiva; afasia; fala/ leitura/ escrita.

\section{RESUMEN}

Este texto aproxima los afásicos que dejan de desarrollar el lenguaje del niño que se había estancado en la escritura, en el momento de su iniciación en el lenguaje. Esta reflexión se basa en prácticas con el lenguaje implicando el habla, la lectura y la escritura; y en la teorización actual desarrollada por la Neurolingüística Discursiva, sobre todo a la luz de Jackson, Freud y Jakobson.

Palabras-llave: Neurolingüística Discursiva; afasia; habla/ lectura/ escritura.

\section{INTRODUÇÃO}

Este texto, vinculado à perspectiva discursiva da Neurolinguística, focaliza a aproximação entre um estado de dissolução da linguagem, a afasia, e a entrada da criança no mundo das letras, que se pode vislumbrar, no primeiro caso, como uma barreira para experienciar, de novo, a língua em uso (Saussure, 1916/1977) e, no segundo, uma barreira para aprender a ler e a escrever. O caminho que percorremos retoma a proposta do Diário de Narciso $^{1}$ (1986/1988) de aproximar a linguagem, na afasia, de processos dialógicos ${ }^{2}$, na aquisição de linguagem, e

*. UNICAMP/IEL. Campinas (SP), Brasil. e-mail: coudry@iel.unicamp.br

**. UNICAMP/IEL-Pesquisadora. Campinas (SP), Brasil. e-mail: soniasellin@uol.com.br

1. O Diário de Narciso, tese de doutorado de 1986, estudo discursivo das afasias, que atende à convocação que Jakobson (1956/1975) faz aos linguistas para investigar a linguagem nas afasias.

2, À época, tais processos integravam a teoria de Aquisição de Linguagem desenvolvida por De Lemos (1981; 1986; entre outras publicações). 
amplia esse encontro com a teorização atual da Neurolinguística Discursiva, com base em Freud ${ }^{3}$, Jakobson, Agamben e Heller-Roazen.

Analisaremos, para tanto, as afasias verbal e assimbólico-verbal descritas por Freud (1891/1973), para relacionar o estado afásico com o da aquisição, sendo o balbucio a lembrança mais antiga na primeira, e a vivência com a língua na tenra infância (Pereira de Castro, 2006), na segunda. Em outras palavras, este texto se ocupa da história do homem que fala a outros homens que falam (Benveniste, 1966/1995) - e de quem vem a não falar ${ }^{4}$-, e rompe radicalmente com a relação estática e biologizante que separa o normal do patológico. Essa é a direção tomada pelo estudo crítico de Freud em que interpreta as afasias como uma modificação funcional sujeita a rearranjos.

Na carta 52 (1896/1990), que escreve para seu amigo e otorrinolaringologista Fliess, com quem mantém longa correspondência, Freud relata que estuda o aparelho de linguagem nas afasias como um aparelho de memória, sujeito a um rearranjo segundo novas circunstâncias - a uma retranscrição, um rearranjo funcional que tem efeitos sobre o estrutural/anatômico. Nesse sentido, a patologia da linguagem ilumina a própria linguagem, isso quando o autor aproxima a parafasia ${ }^{5}$, como processo fisiológico e psíquico, de erros/esquecimentos temporários, decorrentes de um estado meramente funcional (Freud, 1891, p. 96). Ambos involuntários.

Considerar a história do homem que fala e que pode vir a não falar significa tomar o balbucio como porta de entrada para a voz na fala e para as lembranças que advêm das modificações funcionais/rearranjos nas afasias. O balbucio infantil é uma idade na qual toda a vida individual começa (Heller-Roazen, 2005/2010, p. 124), e que, no caso da afasia, recomeça.

Afásicos e crianças não estão no mesmo lugar, mas se encontram, tendo o afásico saído do sistema da língua, na qual tenta reentrar, e a criança tendo revivido seu percurso de sujeito na linguagem em direção a um novo percurso que se inicia na sua relação com a letra e a voz; ou seja, com o que pode ser escrito, inscrito no corpo. Somente a escrita alfabética pode, efetivamente, criar a ilusão de ter capturado a voz ${ }^{6}$, de tê-la com-preendido e inscrito nos grámmata (Agamben, 1978/2008, p. 63).

3. Esclarecemos que o texto de Freud tomado como base neste artigo, As Afasias, de 1891, e os conceitos deles utilizados tais como voz, letra, repetição, inscrição/sensação (memória da sensação do corpo) não são tratados aqui em sua concepção psicanalítica, mas referem-se à teorização freudiana específica desse momento, considerada pelos comentadores da obra freudiana como do período prépsicanalítico do autor.

4. O estudo apresentado neste artigo se vincula ao tema do volume, dis (fluência), na medida em que tal categoria pode ser associada aos desarranjos e rearranjos funcionais propostos por Freud. Nestes termos, trata-se de possibilidades de produção da fala/língua de um sujeito acometido abruptamente por um estado patológico, manifesto por condições temporárias ou mais definitivas, que podem se reestruturar com a inserção do sujeito em práticas com a linguagem.

5. A parafasia observada nos pacientes afásicos não difere do uso errado e da distorção das palavras que as pessoas normais podem observar em si mesmas em estados de fadiga ou de divisão da atenção, ou sob o influxo de emoções perturbadoras (Freud, 1891, p. 29).

6. Vygotsky (1934/1987) também sustenta essa reflexão quando considera que a criança, em suas tentativas de escrita, disseca e analisa as palavras favorecendo sua tomada de consciência do que antes estava automatizado na produção da fala. 
Assim é que, neste texto, com base na teorização proposta, analisaremos dados de afasia verbal (sujeitos VT e WW), assimbólico-verbal (sujeito SB), além de crianças barradas em sua entrada para a leitura/escrita (LS, LP e CS).

Em suma, o acompanhamento longitudinal desses sujeitos, na perspectiva da Neurolinguística Discursiva, tem na interlocução a possibilidade da retificação do vivido (Franchi, 1977), por meio da repetição na/da língua, que atua como o segundo momento do encontro do sujeito com a linguagem (fala, leitura, escrita), sendo o primeiro aquele vivenciado na aquisição da fala/língua.

\section{AFASIA POR JACKSON, FREUD E JAKOBSON}

Consideramos, seguindo Jackson (1874/1915), Freud (1891), Saussure (1916), Jakobson (1941/1980; 1956) e Benveniste (1966), que há uma hierarquia entre as unidades que compõem um sistema, seja o linguístico, seja o cerebral/ psíquico. Neste texto, focalizaremos a hierarquia da dissolução/lembranças envolvida nas afasias verbal ${ }^{7}$ e assimbólico-verbal que, por sua vez, revela um caminho de registros antigos que passa pelo amplo inventário sonoro do balbucio e por lembranças da língua/fala, na tenra infância.

Segundo Freud, as afasias reproduzem um estado que existiu no percurso do processo normal de aprendizado da fala e desorganiza as várias camadas hierárquicas (Benveniste, 1966) da língua, que se rompem; além disso, segundo Jakobson (1941), as afasias provocam uma redistribuição das funções linguísticas, itens que serão considerados na análise dos dados.

Para interpretar o balbucio como a fonte dos sons possíveis produzidos pelo aparelho fonador humano, recorremos a Jakobson (op. cit.) que, com base em Shultz, explica a lei do menor esforço que rege os primeiros sons do balbucio, mostrando uma espantosa quantidade de sons que não se encontram em nenhuma família de línguas. No pico do balbucio, surgem sons inimagináveis, e, quando a criança entra na aquisição de linguagem, deve inibi-los, condição que a faz perder a possibilidade de produzi-los. Tais sons não são facilmente recuperáveis e só retornam em estados de afasia. Segundo o autor, à medida que a criança repete os diversos sons do balbucio, a imagem motora desses sons se impõe, assim como a sua imagem acústica. A impressão acústica de sua própria articulação é determinante para o desenvolvimento normal (auto-ecolalia). Os sons retidos na passagem do balbucio para a língua só podem ser explicados pela própria passagem; ou seja, pela nova função desenvolvida quando este som torna-se som da língua. Jakobson se aproxima de Freud, para quem a criança aprende a reconhecer como idêntico o fonema que produz e o que ouve ser produzido pela repetição que se inicia no corpo, ou seja, pela enervação/propriocepção. Assim, para Freud, o balbucio

7. Esta afasia corresponde às afasias motoras descritas por Luria (1977), ou seja, à afasia motora aferente (AMA) e à afasia motora eferente (AME). 
possibilita a aquisição da fala antes de a criança se submeter à repetição e às regras da língua ${ }^{8}$.

\subsection{Aproximação entre criança e afásico}

O aparelho de linguagem concebido por Freud é um aparelho associativo, que se estrutura para além do território da linguagem. Nesse aparelho, a palavra adquire significado por meio de sua associação com a representação de objeto que, por sua vez, é também um outro complexo de associações integrado pelas mais diversas impressões visuais, auditivas, táteis, cinestésicas. Decorre disso a interpretação das afasias como interrupções de associações/percepções, de várias ordens, que tocam a palavra, tal como a concebe. A hipótese de Freud é a de que a representação de palavra (seu elemento acústico) está relacionada à representação de objeto (seu elemento visual).

A aproximação entre criança e afásico é possível pelo conceito de dissolução entre o aprendido e o automático, do neurologista inglês Huglings Jackson (1874), que caracteriza o estado afásico como uma impossibilidade para formar proposições e relacionar palavras. Para o autor, na afasia, há dissolução da fala, o que corresponde à sua redução a aspectos automatizados, emocionais, sendo a linguagem intelectual (formada de proposições intencionais) dissolvida. Isto aproxima a fala do afásico verbal da fala da criança que começa a entrar na linguagem, contribuição que Freud leva para seu estudo das afasias. Para Jakobson (1941), tal dissolução corresponde à deterioração do sistema fonêmico, e o afásico, diferentemente da criança, oferece um sistema em reestruturação com o que ficou, o que pode ser relacionado com os rearranjos propostos por Freud. Esse autor, com base na psicofisiologia de Fechner, considera que toda experiência do sujeito deixa marcas na relação do fisiológico com o psíquico que constitui o substrato neural. Tais marcas se configuram como registros de um processo que tem início com a percepção que, por sua vez, se vincula à associação: dois termos com os quais descrevemos diferentes aspectos de um mesmo processo (p. 71).

Nos dados apresentados neste texto, como se verá, se a percepção está afetada, há efeitos na associação, e uma associação pode dizer muito da percepção em causa. Assim, durante a vida, novos registros são feitos, outros são modificados e todos passam pela relação entre percepção e associação, o que pode ser revivido/

8. Foi o que aconteceu com RD, uma criança, acometida por dois Acidentes Vasculares Cerebrais aos 8 meses de idade, que tem como seqüela uma paralisia cerebral que afetou o aparelho fonador em seu aspecto motor, envolvendo estruturas de comando da deglutição. Entretanto, tendo passado pela impressão da inervação no balbucio, cujo registro no corpo como memória, somado à representação acústica da fala do outro, entrou para o mundo da leitura e da escrita. A condição de ter passado pelo balbucio contribuiu fortemente para que RD fale pela escrita. RD vive a linguagem imersa nos aspectos sociais da oralidade a ponto de cochichar quando quer que alguém não escute o que está falando para outra pessoa, sem mesmo perceber que não fala. 
recordado, por modificações realizadas pela inevitável condição humana de associar $^{9}$ e superassociar.

Para os nossos propósitos, destacamos tanto a afasia verbal, em que estão interrompidas/modificadas as associações entre os vários elementos de representação de palavra (campos corticais receptivos e motores), o que corresponde à chamada afasia motora, que pode vir acompanhada de agrafia e alexia para letras (sujeito WW) quanto a afasia mista, assimbólico-verbal, que incide no interior das associações verbais, como também na perturbação de suas conexões com as associações de objeto, o que tem efeitos na compreensão da linguagem (sujeito SB).

\subsection{Velho e novo na afasia}

As afasias modificam a familiaridade que o sujeito tem com a língua (fala, leitura e escrita) e com o exercício da linguagem; na afasia motora, descrita por Freud (1891), há dissolução de uma das diversas possibilidades de repetição que caracterizam a fala humana. Tal condição do sujeito afásico modifica a relação entre o automático/voluntário, seja para produzir os sons da língua articulados com outros, para recompor as palavras da língua, seja na combinação com outras, para formar unidades de sentido mais amplas que, por sua vez, se relacionam com outras no fluxo contínuo entre os dois eixos sintagmático e paradigmático da cadeia verbal (Jakobson, 1956).

Na literatura sobre afasia no século XIX, sobretudo em Jackson, e no século XX, em Goldstein (1948) e Luria (1977), é possível identificar essas corelações: automático e voluntário; velho e novo. Como vimos, a afasia produz uma modificação funcional no cérebro e na linguagem fazendo com que a barra divisória entre o normal e o patológico perca muito de sua função diferenciadora (Coudry, 2008). O reconhecimento do que é velho e novo se dá no tempo possibilitado pela linguagem, falada e lembrada (memória). É justamente na mobilidade da barra que separa o velho do novo que incide a afasia (op. cit.); tal mobilidade possibilita a circulação da linguagem e do sujeito em trajetos velhos e novos, lembrados e esquecidos, associados e superassociados; esta é uma condição que se modifica nas afasias verbal e assimbólico-verbal focalizadas neste texto.

A impossibilidade de repetir caracteriza muitos afásicos que, mesmo sob comando verbal feito por seu interlocutor, não conseguem repetir uma palavra, mas, diferentemente, na fala, em interação com o outro, eles dizem a palavra que não podem repetir (sujeito SB). É de Jackson o exemplo em que, em resposta a seu interlocutor que solicitou ao afásico que repetisse a palavra não, ele disse: Não,

9. Para Freud, em relação aos substantivos, a associação se refere aos primeiros significados e conceitos que uma palavra traz; já a superassociação se dá entre significados que se sobrepõem aos primeiros. Tendo sido influenciado pela teoria da dissolução de Jackson, Freud assume que as superassociações são prioritariamente afetadas, no caso, por exemplo, de processos normais ou patológicos que incidem sobre esquecimentos/lembranças, aprendizados recentes, aprendizado de segunda língua (Freud, 1891). 
doutor, eu não consigo dizer "não". Em nossa interpretação, o afásico não repete porque a palavra a ser repetida soa como nova, sendo que, na fala, dirigida ao outro e ancorada pelo sentido ela soa como velha, e vem à tona, ativada pelo automático/ involuntário e, por isso, não escuta/percebe sua fala. Freud (1891) retoma essa questão considerando que, nas afasias, uma das modificações importantes na relação do sujeito com a língua diz respeito à relação das palavras, seus segmentos e suas relações com outras; o que suspende a possibilidade de comandar a própria fala e de exercer atos de fala que representem a intenção do afásico. O discurso custa a fluir e se apresenta entrecortado (o chamado não fluente), com predominância de nomes em cuja produção se manifestam tanto a afasia quanto as várias possibilidades de explicitar suas relações sintático-semânticas.

Na afasia verbal, retomando Freud (1891), o sujeito perde a função corretora que atua na aproximação entre a imagem sonora da palavra falada (segunda imagem sonora) e a imagem cinestésica da palavra (primeira imagem sonora). Segundo as teses deste autor, é como se a afasia modificasse as relações estabelecidas culturalmente, que interferem na interpretação e produção do sentido, e se apresentassem como novas, sendo o velho da língua (fala, escrita e leitura) difícil de ser reconhecido, e associado (Coudry, 2008; 2010b; Bordin, 2010).

Segundo Freud, portanto, o velho se apresenta como novo na afasia. Se antes a fala transcorria como natural, incompleta, com todas as marcas da fala humana, no estado afásico as palavras não estão mais à disposição, havendo uma interrupção no fluxo do discurso que afeta as condições em que se organiza a língua: o sistema sonoro, fono-articulatório, o fundo lexical comum, os arranjos sintáticos, as leis pragmáticas. $\mathrm{O}$ afásico sabe o que quer dizer, mas os gestos articulatórios do velho da língua lhe fazem falta, o que pode redundar em novos arranjos que se configuram como parafasias, jargão, estereotipias, bem como o retorno a sons do balbucio e a lembranças da infância.

A reflexão de Freud sobre a relação entre as impressões cinestésicas e acústicas da palavra nos leva a interpretar a dificuldade do afásico (e do não afásico) de dizer uma palavra que quer dizer - o que corresponde ao chamado fenômeno da ponta da língua - como incidindo na segunda imagem sonora da palavra (escutada de sua fala e da fala de outros). Esse fenômeno acontece com afásicos e não afásicos, quando esquecem temporariamente nomes, mas sabem quais são (Freud, 1901/1969); ambos conservam a primeira imagem sonora da palavra, que corresponde à impressão da inervação da palavra, fazendo falta a imagem cinestésica para completar o ato motor para produzir a imagem acústica da palavra na língua.

\section{RETORNO DO BALBUCIO E ESQUECIMENTO DA LÍNGUA}

A reflexão de Jakobson (1941) e Freud (1891) sobre a relação entre afásico e criança leva a pensar que todos os sons são possíveis no balbucio ${ }^{10}$ e ficam

10. Diferentes estudos reconhecem o balbucio como um fenômeno presente na criança surda e ouvinte. Petitto \& Marentette (1991), em estudo realizado com bebês surdos e ouvintes (desde o 
registrados no corpo da criança pelas impressões cinestésicas, motoras e sonoras. Muitos desses sons são inibidos quando da entrada em um sistema linguístico, e, na afasia, retornam, sendo desinibidos/lembrados, nas tentativas de o afásico seguir, de novo, as constrições da língua. É justamente esta condição que permitiu a esses autores aproximar o afásico motor da criança no processo inicial de aquisição da linguagem. Ambos não exercem a função corretora da linguagem estando fora do sistema da língua. Trata-se do motor puro.

\begin{abstract}
Enquanto não aperfeiçoamos nossa língua, a segunda imagem sonora, embora associada à primeira, não é necessariamente idêntica a ela. Nessa etapa, que é a fase do desenvolvimento da linguagem na infância, empregamos uma língua construída por nós mesmos, ao associar outros sons das palavras com o que nos mesmos produzimos, nos comportamos como afásicos motores (Freud, 1891, p. 87. Tradução das autoras)
\end{abstract}

Segundo Jakobson, o balbucio tem que ser inibido, não tem função de signo, o que acontece quando a criança entra no sistema. Essa formulação corresponde ao que Agamben (1978/2008) denomina como pura língua. Nos seus termos, para falar o homem se expropria de sua infância; o que também corresponde ao referido motor puro de Freud.

A reflexão de Heller-Roazen (2005/2010) sobre o conceito de substrato de Bredsdorff pode ser transposta para o estudo da afasia, no sentido de que nela há um resíduo que persiste que é o elemento esquecido e secretamente retido e que retorna (p. 68). Como vimos, o balbucio faz parte da história do sujeito falante, sendo marcado no corpo como propriocepção e memória.

Conforme Agamben (1978), o lugar do afásico, saindo do sistema, é a possibilidade de haver lembranças ${ }^{11}$ do que fora esquecido do balbucio que voltam a ressoar. Ainda segundo este autor, a infância da linguagem é uma experiência muda e retorna na afasia, o que, para o não afásico, é impossível. No caso da afasia, o afásico lembra e esquece a própria língua, lembrança e esquecimento na acepção de Freud, ou seja, como acesso a caminhos interrompidos pela modificação funcional que suscitam rearranjos no contínuo da fala. As tentativas mal sucedidas são preenchidas pela memória proprioceptiva do balbucio do que um dia se tornou língua, contando com a possibilidade do retorno de sons que não se estabilizaram no sistema da língua materna que o sujeito falava antes de ser afásico (cf. nos dados a descrição do sotaque do sujeito VT).

nascimento até 14 meses), detectaram duas formas de balbucio: silábico e manual. As vocalizações são intensificadas nos bebês ouvintes e interrompidas nos bebês surdos que, por sua vez, intensificam as produções manuais. Para Oller e Eilers (1988), o balbucio acontece em crianças ouvintes e surdas, com diferenças quantitativas e qualitativas.

11. Ver Anexo 1. 


\section{SUJEITOS ${ }^{12}$ E DADOS}

1) WW, 42 anos, comerciante, destro, apresenta uma afasia verbal, decorrente de Acidente Vascular Cerebral isquêmico (AVCi), na região da artéria cerebral média do hemisfério esquerdo. Segundo o estudo de Freud (1891), tal afasia é de natureza motora e prejudica a transmissão de estímulos que se conectam com os músculos da linguagem, com efeitos na seleção e concomitante combinação de segmentos fônicos e de palavras (Jakobson, 1956). Com essa afasia, que incide no aspecto motor da fala, com repercussão na leitura e na escrita, se desfaz o forte vínculo entre o sonoro e o motor, bem como a relação de concomitância entre eles, o que dificulta a produção verbal, além de torná-la morosa (não fluente).

O conjunto de dados de WW privilegia a escrita como um lugar estruturante para os seus dizeres. É por meio da escrita de palavras fraturadas e rejuntadas que ele vai se ajustando à repetição da língua, o que exige rearranjos que, na maioria das vezes, não se mostram funcionais. Para Freud, a repetição é um contexto favorável para a ocorrência de memória, entendendo-se esta como associação entre memórias continuamente compostas, decompostas e recompostas pelo próprio processo que as atualiza como lembranças. Desse modo, não há o que se recorda, mas modos de construir o que se recorda. O esquema neuronal envolvido em memórias repetidas promove no cérebro o que Freud denominou de encurtamento ou abreviação funcional. Trata-se de processos automatizados pela repetição em que não é mais necessário percorrer todo o caminho neuropsíquico para a realização de uma atividade, ou seja, a experiência com a escrita possibilita ao escrevente que ele não pense mais na letra ou no movimento das mãos para escrever uma palavra. Contrariamente a isso, é justamente a busca pelo que um dia foi automático, encurtado funcionalmente, que faz com que WW dispenda um grande esforço para não apagar o significado que pretende partilhar com a investigadora, valendo-se para isso de diferentes cadeias associativas sonoras e visuais, com a finalidade de compor a imagem escrita do significante - por meio de fragmentos sonoros da fala, fragmentos visuais da letra, da recordação do tamanho/ partes da palavra, de palavras de outra língua - para chegar ao velho da língua. No trabalho linguístico realizado por WW, a presença da atividade epilinguística (Coudry, 1986) sinaliza o comparecimento de um sujeito que não desiste do papel de falante na interlocução com o outro.

Em dezembro de 2010, foi realizada uma avaliação fonoaudiológica por Isb em que foi constatado que WW tem preservada a produção dos sons do quadro

12. O Centro de Convivência de Linguagens - CCazinho (IEL/UNICAMP)) é um espaço de intervenção, mediado pela relação fala, leitura e escrita, no processo de aquisição e uso da escrita de crianças que receberam um diagnóstico que compromete tal processo e sua permanência na escola (Coudry, 2006). LP e LS frequentam o CCazinho em sessões individuais e coletivas; CS é acompanhada individualmente por Isb em clínica particular. O Centro de Convivência de Afásicos CCA (IEL/FCM/UNICAMP) é um lugar de convivência entre pessoas afásicas e não-afásicas que se envolvem nas mais diversas atividades linguageiras que caracterizam os sujeitos falantes do Português Brasileiro (PB). SB, WW e VT participam do CCA em sessões individuais; os dois últimos participam também de sessões coletivas. 
Cadernos de Estudos Lingǘlsticos (54.1) - Jan./Jun. 2012

fonético-fonológico do PB. Nessa sessão, WW propôs à investigadora, por meio de uma fala composta de segmentos de palavras e gestos, retomar tal quadro e escrever palavras que ele pensou/associou e não pode dizer. Tal atividade remete à relação associativa que une termos em ausência numa série mnemônica virtual (Saussure, 1916). Entretanto, a afasia de WW apaga o caráter virtual de suas associações tornando-as explícitas.

a) Para o som /k/, a palavra a ser escrita é $C O R A C ̧ \tilde{A} O$. WW escreve a sílaba $C O$, deixa um espaço, escreve $C \tilde{A} O$ e, em seguida, acrescenta a cedilha. Depois, WW lê a sua escrita incompleta $(C O \quad C \tilde{A} O)$ como CORAÇÃO e acrescenta a sílaba $R O$ no meio da palavra, o que a investigadora estranha e ele, finalmente, corrige para $R A$.

\section{CORAÇÃO}

b) Para o som /b/, WW pretende escrever a palavra cerveja.

\section{BEBA BEBIDA BIER}

WW escreve bebi, a investigadora interpreta como bebê e ele reescreve a última vogal, que transforma a palavra em beba; e a investigadora não compreende. WW lê a palavra bebi como bebida, guiado pelo sentido, e escreve bebi de novo, completando-a com a sílaba $d a$. A investigadora considera que WW chegou à palavra pretendida, mas ele não concorda e ela lhe diz: coca-cola, refrigerante. De novo, WW não aceita e escreve $b i$, o que dificulta a compreensão da investigadora. Em seguida, WW lê o que escreveu - bi - como bier - e completa a escrita com er (bier). Quando a investigadora diz cerveja, ele fala: É isso! Conhecendo a palavra bier, WW realiza uma tradução intrasemiótica (Jakobson, 1959/1975) para cerveja, preservada no seu estado afásico. O trabalho linguístico cognitivo de WW é de natureza metonímica (Jakobson, 1956) - de bebida para bier - e mostra um sujeito atuando na unipolaridade da afasia de predomínio metonímico/ sintagmático (op. cit.).

c) Para o som /g/, a palavra a ser escrita é Gabi, apelido de sua filha.

\section{BAGI BABI GABI}

WW escreve $G A B I$ como $B A G I$, o que mostra uma inversão espacial na ordem das consoantes, mantendo a posição das vogais. Na segunda tentativa de aproximar a escrita da palavra a sua imagem cinestésica e acústica, aparece a repetição da letra $b$, na escrita de $B A B I$; tendo a investigadora chamado sua atenção para a mudança na estrutura sonora da sílaba $G I$ para a sílaba $G A$, WW pode ajustar a imagem cinestésica da palavra a ser escrita para $G A B I$, nome familiar em seu cotidiano. 
d) Em seguida quis escrever o nome do filho, Guilherme.

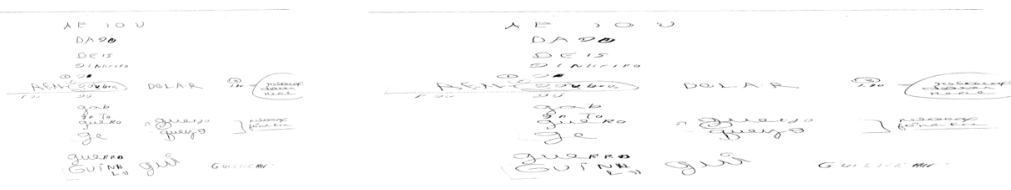

A escrita dos nomes dos filhos começa com a mesma letra, $G$. Entretanto, o nome do filho exige, ortograficamente, a presença da escrita complexa (CVV) gui. O caminho percorrido por WW é: guero, ge, gueijo, queijo, guerro, GUINH, LH e gui (apelido do filho). WW busca pela diferença entre a oclusiva surda [k] e sonora $[\mathrm{g}]$ representadas pelas letras $g$ e $q$, como se vê em gueijo e queijo. A hipótese da investigadora (queijo) é refutada por WW. Depois de ter escrito gui, WW mostra que sabe que se deve seguir um dígrafo, mas oscila entre $r$ (guerro), nh (Guinh) $e$ lh, se aproximando da palavra que quer escrever. WW retoma a escrita da palavra gui, deixa um espaço, escreve $m i$, volta a olhar os dígrafos e escreve the. A investigadora the chama a atenção sobre a falta da coda da sílaba complexa, e ele insere o $r$.

O movimento da escrita para a leitura e a fala, e suas combinações, que WW percorre para escrever com sentido explicita as associações e oscilações que faz, dando visibilidade ao que Freud define como encurtamento funcional, cuja falta o faz percorrer um longo caminho até chegar ao que pretende; entretanto, as associações que faz estão, em alguma medida, pelas diferentes entradas que a palavra possibilita, próximas da palavra em questão.

2) $\mathrm{SB}^{13}, 47$ anos, professora de história, destra, apresenta uma afasia assimbólicoverbal, decorrente de um AVCi na região têmporo-parieto-occipital esquerda. Com seu estado afásico, modifica-se funcionalmente a relação entre a representação de palavra e a representação de objeto, sobretudo no aspecto sonoro. Sua afasia se manifesta em várias circunstâncias: na busca da palavra que nomeia um objeto; na lembrança de formas esquecidas da língua; na entonação e infantilização da pronúncia; e no não reconhecimento da própria fala.

Os excertos de situações discursivas abaixo apresentados, ocorridas no período de junho de 1997, entre SB e a investigadora (Imc), mostram formas linguísticas concorrentes e uma entonação que representa lembranças de uma fala não mais falada por ela na vida adulta. Tendo a investigadora perguntado a SB se percebe/escuta sua própria fala, ela diz:

a) SB. - Não se escuto

Com essa fala, SB mostra a sua não aproximação da fala do outro, ou seja, da língua (Não me escuto) e, como se verá no próximo trecho, há uma alternância

13. A afasia de SB foi estudada por Coudry (1997) e Balieiro (2001). 
entre formas linguísticas que se sobrepõem. No mesmo propósito, a investigadora pergunta:

b) Imc.- Você percebe que cê acerta? Quando você fala certo, você percebe?

SB. - Ouvo, ouço. Tem coisa eu ouço. Ouvi, eu ouvo. Eu ouvo, eu se escuto...

Segundo Freud, escutar com compreensão significa que, a partir do elemento sonoro, abrem-se possibilidades de associação, de maneira que repetimos para nós mesmos a palavra escutada, o que a afasia de SB a impede de fazer, dificuldade que se manifesta na falta de controle sobre a não coincidência entre as imagens motora e sonora da palavra a ser dita.

Ouvir eu ouvo (não se escutando) representa um tipo de lembrança que mostra a hierarquia da dissolução e sua repercussão em diferentes subsistemas da língua. Trata-se de lembranças de registros antigos, de uma fala não padrão, do interior paulista, de uma família com pouca escolaridade, que SB aprendeu na tenra infância. Na vida escolar de SB, que culmina com sua formação como professora de história, ela aprende e usa formas da variedade padrão, que sofrem o impacto da afasia, o que faz emergirem lembranças de registros antigos, em detrimento de superassociações mais recentes.

Entretanto, SB deixa marcas de uma subjetividade afetada pela afasia (Coudry, 2010a) que se vê, no próximo excerto, na alternância entre a $3^{\mathrm{a}}$ pessoa (fica cansada; lê) e a $1^{\text {a }}$ pessoa, marcadas tanto no pronome pessoal quanto na forma verbal. Esse caminho mostra a atividade epilinguística ${ }^{14}$ funcionando na reestruturação da sintaxe da língua.

c) SB. - Fica cansada, porque eu fico, eu (...) lê, eu ouvo tudo. Escrever, eu fico ali procurando saber o que acontece.

É interessante observar o caminho de SB na busca do equilíbrio interno (eu comigo: alternância entre $1^{\mathrm{a}} \mathrm{e} 3^{\mathrm{a}}$ pessoas para se referir a ela mesma) quanto externo (eu com o outro: incompreensão da fala do outro). Seguindo Culioli (1990), é como se o sujeito não pudesse se livrar da atividade epilinguística, inerente à condição de falante de uma língua natural. Argumentamos, para os nossos propósitos, que, mesmo na afasia, a atividade epilinguística de SB continua ativa, ainda que haja indícios de sua desorganização. Essa atuação deixa ver um sujeito e seu trabalho linguístico (Franchi, 1977; Coudry, 1986), às voltas com sua reentrada na língua.

Os efeitos da não percepção de sua fala e da fala do outro fazem com que, em certas situações, SB se mostre no limite de sua condição afásica, chegando a entrar em um caminho que conduz à dissolução (Jackson, 1874; Freud, 1891; Jakobson, 1941): SB diminui a intensidade vocal e produz sons impossíveis de

\footnotetext{
14. Culioli (1990) define a atividade epilinguística como não consciente pelo fato de ela comandar as representações linguageiras as quais não se tem acesso, diferentemente da atividade metalingüística, consciente. Segundo esse autor, a atividade epilinguística designa a parte não consciente da atividade de linguagem, em sua função de organização das camadas hierárquicas do sistema, afetadas na afasia de SB.
} 
serem compreendidos, o que acontece pela máxima desorganização da atividade epilinguística.

d) SB. - que eu sei, eu falo, mas outra ... eu não falo assim. Na fala eu dispi ... ah ... (queda de intensidade vocal e produção de sons ininteligíveis)

Em outras palavras, SB não reconhece os sons que produz e os que ouve como sendo idênticos, por isso não repete, o que dificulta seu reconhecimento (Freud, 1891). Nas tentativas de aproximação de sua fala da fala do outro, SB, muitas vezes, sai do sistema da língua e procura um caminho para sua reentrada, mas, sem o ajuste da imagem motora e sonora da palavra a ser falada, não consegue. É o que se verá em suas tentativas de nomear o objeto chave. A investigadora, segurando suas chaves do carro, pergunta a SB o nome desse objeto:

e) SB. - Ele é ... eu sabia... pegar o carro, a gente assim põe o carro, pra por aqui (segurando a chave na posição correta para dar a partida), põe no carro ... Imc - Isso, põe no carro, exatamente ... ch ... ch ... (fornecendo o prompting), cha ...

SB. - cha, a chada, chatália ..., como fala ? Esqueci como fala ... a chave, chave.

Para dizer chave, SB segue outro caminho, em que se nota a redistribuição da função (Jakobson, 1956) de nomear para a de descrever a cena com o corpo. Faz isso por meio dos gestos de dar a partida do carro, quando, então, a palavra ganha contexto para ser verbalizada, o que corresponde à tradução intersemiótica (Jakobson, 1959), preservada na afasia (Coudry, 2008). Observemos que o esboço motor e sonoro da investigadora [S] não facilita, na acepção de Freud, que SB diga chave, o que, na sequência, se desintegra nas parafasias neologizantes: chada, chatália. Tais parafasias revelam que SB percebe mal sua fala e também associa mal. No entanto, ao mesmo tempo, essas tentativas mostram que SB guarda o segmento inicial da palavra em questão [S]. Chamamos atenção para o fato de que a teorização desenvolvida na ND leva a considerar o caminho do sentido como uma condição favorável para que possíveis rearranjos reestruturem a fala.

A afasia de SB traz como outra lembrança o baby talk, marcado tanto pela entonação quanto por infantilizar a pronúncia da palavra esquece, que consegue dizer ao nomear a chave, no excerto abaixo:

f) SB.- É difícil pra mim! a ... assim ... às vezes eu esqueço, é muita dificuldade ... pe...pe... Eu pego o jornal, mas me cansa demais. Comprei revista, a Veja, hoje eu dou uma olhada, sabe? Eu tento olhar, cansa, eu fico ..., mas é ...eu sei , até parece que a gente esteci, né?

O baby talk ocorre justamente diante da dificuldade de SB explicar o que acontece com sua fala. Nesse trajeto, SB parece habitar o esquecimento da língua, preenchido por lembranças que se lhe impõem e a fazem retornar a um momento na infância da linguagem (Agamben, 1978).

Considerando a alternância entre ouvo e ouço, no próximo trecho, vemos que é a interlocução, conceito chave na visão discursiva da afasia (Coudry, 1986; Coudry e Freire, 2010), que promove os rearranjos que SB faz para perceber sua 
fala, mostrando a linguagem como atividade e trabalho - eu escuto - (Franchi, 1977) que reconstitui o sujeito no seu dizer. Isso favorece a SB o acesso a camadas mais sofisticadas do sistema (Jakobson, 1941), o que lhe possibilita superassociar, deslizando para outro significante (Freud, 1891) - eu escuto - uma forma verbal que soluciona o impasse entre um verbo irregular (esquecimento morfológico) e seu sinônimo, um verbo regular da primeira conjugação: duas formas de permanecer no mesmo sentido.

g) A investigadora provoca SB para se escutar:

Imc. - Por que você fala eu ouvo?

SB. - $\tilde{A} h$ ?

Imc - Eu ouvo?

SB. - Eu falo?

Imc. - Você fala eu ouvo tudo.

SB. - Eu escuto.

Imc. - ${ }^{* 15} \mathrm{Eu} \mathrm{ouço.}$

SB. - * Eu ouvo. Ah, pera lá, eu ouço.

Segundo Saussure (1916), o significante e o significado evocam associações, o que acontece quando SB substitui ouvo por escuto, o que é possível pela ativação da atividade epilinguística, sem o que ela continuaria não percebendo ${ }^{16}$ sua fala: $\tilde{A} h$ ?

3) VT, 53 anos, destra, funcionária pública aposentada, foi acometida por um extenso AVCi fronto-têmporo-parietal esquerdo, e apresenta um resíduo de uma língua na outra creditado ao balbucio (Heller-Roazen, 2005, p. 68), ou seja, um sotaque de língua inglesa marcado por um forte $R$ retroflexo [I], repetido continuamente com pausas que representam limites entre unidades, lembrando muito o do inglês americano, língua que não falava antes de tornar-se afásica. Tal produção é acompanhada do gesto de mastigar com sonorização nasal. Segundo Heller-Roazen (2005), Freud considera que a afasia

(...) não representa um tipo de esquecimento, mas exatamente o oposto: uma forma aguda de rememoração, na qual os indivíduos, não desejosos ou incapazes de "rearranjar" ou "retranscrever" os "signos" de suas percepções, se lembram, por assim dizer, demais, ficando condenados à recorrência perpétua de um enunciado à custa de todos os outros (Heller-Roazen, op cit., p. 123).

É o que ocorre com VT, em cuja fala algumas poucas palavras entram no lugar de todas as outras e só deixam de invadir sua fala quando seu interlocutor interfere.

15. $\mathrm{O}$ asterisco indica uma sobreposição de vozes entre a investigadora e SB.

16, Abordagens assentadas em testes psicométricos para avaliar e tratar as afasias excluem a interlocução de suas práticas e, assim, interpretam a fala de SB: $A h$ ? apenas como falta de compreensão de sua parte, negando-lhe o contato com suas dificuldades para reestruturar a fala. Diferentemente, nos estudos linguísticocognitivos empreendidos por uma Neurolinguística de tradição discursiva, como a que exercemos, destaca-se o papel da interlocução como constitutivo e restaurador da linguagem nas afasias. 
Nas situações dialógicas entabuladas com VT, vemos que ela precisa, para entrar de novo no sistema, que seu interlocutor lhe forneça o esboço motor e sonoro das palavras, e ela lhe dá continuidade. Ou seja, VT só acessa o sonoro e o motor pelo sonoro e o motor do outro, mas não inicia a fala. Na tentativa de iniciar a fala tem lugar o sotaque de americana ou palavras que se repetem à sua revelia (dedo, todo dia e o nome do marido). Sem o esboço do outro, VT sai da língua e retorna a registros esquecidos do balbucio, de onde vem essa experiência de vocalização, antes de ser língua: um R que não conhece interrupções nem fraturas (op. cit., p. 54). Nos casos graves de afasia como a de VT, rompe-se a superposição funcional dos sistemas digestivo e respiratório envolvidos no funcionamento do aparelho fonador (cf. Anexo 1), o que permite estender o conceito de redistribuição das funções linguísticas para funções mais primitivas. O efeito é um retorno à função principal do aparelho digestivo, que interfere nos restos de linguagem produzidos por VT, que, do som contínuo do $R$ retroflexo [I], desliza para a mastigação, acompanhada de sons nasais.

Retomando a reflexão de Agamben (1978), é possível identificar, na afasia, formas que remetem à in-fância do homem e, para o autor, infância e linguagem parecem, assim, remeter uma à outra, em um circulo no qual a infância é a origem da linguagem e a linguagem a origem da infância (p. 58). Focalizamos, na análise de VT, o retorno a sons do balbucio e, na análise das crianças que serão apresentadas a seguir, o foco é o balbucio como vivência incompleta do traço de sonoridade, com efeito na voz que se materializa na fala e na escrita. Para VT, o balbucio entra no lugar dos sons da língua, e, para as crianças, se apresenta como impedimento para reconhecer uma diferença que atinge todo o sistema da língua. Em ambos os casos, isso dificulta a concomitância entre o motor e o sonoro, ficando o afásico e a criança em condição semelhante, ou seja, barrados na língua (letra e som).

\section{4) Crianças}

Como vimos, o aparelho de linguagem, tal como concebido por Freud (1891), considera a palavra como um conceito complexo, psicológico, de associações de origem visual, acústica, cinestésica, dentre outras, que adquire seu significado na associação com a ideia de objeto (conceito/representação). Para as associações de objeto a imagem visual é imagem soberana, e, para as associações de palavras, a soberania está com as imagens acústicas. $\mathrm{O}$ autor vincula a leitura e a escrita às associações de palavras, considerando que quem sabe ler e escrever não lê ou escreve letras, mas sentidos presentes na fala/língua. Assim, ler e escrever pressupõem a fala, ou seja, a variedade pela qual a criança entra na língua. Para o autor, aprendemos a falar associando a imagem sonora da palavra com a impressão da enervação da palavra, quer dizer, as impressões sensoriais procedentes dos órgãos da fala. Entretanto, nem todas as crianças desenvolvem adequadamente a memória associativa entre a imagem sonora da palavra (sequência de sons em combinação) e as impressões proprioceptivas (imagens cinestésicas) correspondentes à produção de cada um desses sons. Rodrigues (1989) explica que o sistema nervoso central, 
do ponto de vista da coordenação dos gestos articulatórios envolvidos na produção da palavra, pressupõe um grande número de comandos motores predeterminados e implicados na memória e seleção de cada um desses gestos. Além disso, a posição dos órgãos fonoarticulatórios (OFA) no contexto fonético/fonológico gera uma organização espaço-temporal intrinsecamente associada a ela, que não pode ser zerada a cada gesto, motivando certo grau de sobreposição espaçotemporal nos gestos articulatórios adjacentes: mudanças em uma delas implicam a reorganização da outra e vice-versa (op. cit., 1989, p. 28).

As crianças LS ( 9 anos, $2^{\mathrm{a}}$ série), LP (9 anos, $3^{\mathrm{a}}$ série) e CS (8 anos, $3^{\mathrm{a}}$ série) falam sem que a sonoridade se constitua como valor de diferença (Saussure, 1916). Entendendo que, a partir da atividade das pregas vocais (cf. Anexo 1), as representações acústicas são informadas em traçados na forma de ondas, podemos dizer que tais crianças são ineficientes quanto ao traço de sonoridade, fazendo falta os registros do período de balbucio quando a fisiologia funcional do aparato vocal para o traço marcado fica incompleta e não se inscreve no corpo como memória.

Essas crianças não tiveram problemas na aquisição e uso da linguagem nas vivências com a língua, nos ambientes psico-afetivos em que convivem, e se mantiveram em um conforto articulatório que possibilitou que fossem compreendidas por outros. Isso se dá porque o sentido das palavras faladas, mesmo quando não se aproximam da língua pela não marcação do traço de sonoridade, é protegido tanto pelo contexto quanto pela tolerância de leis pragmáticas, que aceitam que uma criança pequena fale diferentemente do adulto. Entretanto, quando essas crianças, em idade escolar, entram nos processos de leitura e escrita, há uma nova exigência: a escrita alfabética pressupõe uma univocidade de registro, o que a criança desconhece.

Analisando dados de fala e de escrita dessas crianças, observamos que a falta da sonoridade na voz, resultante do balbucio, retorna como uma resistência à constrição da língua escrita. Trata-se de uma propriocepção incompleta do sistema fônico que exige explicitação, ou seja, a criança precisa percorrer o sistema fônico por inteiro para distinguir os sons marcados e não marcados. Diferentemente da fala, a escrita exige coincidência entre a duplicidade da imagem motora e sonora da letra e a imagem motora e sonora do nome da letra. Vejamos como essas crianças falam e escrevem ${ }^{17}$ :

LS: Eu não costei de ficar esperanto.

LP: O meu pirimo fai firaqui.

CS: Eu fui na sorfeteria comprar sorfete.
Eu não gostei de ficar esperando.

O meu primo vai vir aqui.

Eu fui na sorveteria comprar sorvete.

No início do acompanhamento fonoaudiológico/neurolinguístico das crianças, vemos que a sonoridade, insuficientemente marcada na fala, é flagrada na escrita e impõe a necessidade da expansão do sistema fônico como garantia de uso do sistema alfabético do PB.

17. Para os propósitos do texto só serão analisadas as palavras em destaque. 
Na continuidade do acompanhamento de cada uma dessas crianças, a falta de memória em seu corpo, quanto à propriocepção da sonoridade, determina sua grande dificuldade em lidar com a nova propriocepção/produção de fonemas sonoros que precisa de tempo para ser automatizada. Não se trata, portanto, de estabilizar os novos sons com sua representação visual (Bordin, 2008). Trata-se de rearranjar a associação proprioceptiva, motora e sonora entre esses sons e sua representação gráfica ${ }^{18}$. Sobre isso, as crianças dizem que: acho que é um e é outro (LS); não percebo se estou falando e escrevendo como deveria ser (LP); quando leio em voz alta parece que está tudo errado, fico sempre na dúvida (CS).

Em cada situação de fala e de escrita de palavras com esses sons/grafemas, essas crianças ficam às voltas com uma decisão que tem que ser tomada rapidamente no contexto espaço-temporal do gesto da fala e/ou da escrita. Tal decisão quanto à dupla coincidência motora e sonora da letra - entre a fala do nome da letra e a fala do som da letra e a representação gráfica da letra (Bordin, 2010) - envolve, em cada contexto de palavra, diferentes possibilidades de escolha baseadas no fato de que a criança pode falar:

$$
\begin{aligned}
& \text { - } / \mathrm{t} / \text { no lugar de /d/ e escrever t (não coincidência entre som e letra) } \\
& \text { - } / \mathrm{t} / \text { no lugar de /t/ e escrever d (não correspondência entre som/letra) } \\
& \text { - } / \mathrm{t} / \text { e escrever } \mathrm{t} \text { (coincidência entre som e letra) } \\
& \text { - } / \mathrm{d} / \text { no lugar de /t/ e escrever d (não coincidência entre som e letra) } \\
& \text { - } / \mathrm{d} / \text { e escrever } \mathrm{t} \text { (não correspondência entre som e letra) } \\
& \text { - } / \mathrm{d} / \text { e escrever d (coincidência entre som e letra) } \\
& \text { O mesmo acontecerá com todos os outros pares de fonemas plosivos e } \\
& \text { fricativos sonoros. }
\end{aligned}
$$

Assim, para LS, LP e CS, o processo de leitura e de escrita se estrutura como uma instância de desestabilização da produção da fala quando a criança passa a marcar na escrita o valor da diferença entre sons próximos, estabilizando esse aprendizado primeiro na escrita e depois na fala. Experimentar a impressão da inervação sonora da diferença entre o som marcado e não marcado e associála adequadamente significa construir e usufruir de uma memória que demanda atenção e tempo para ser automatizada, condição em que a atividade epilinguistica exerce sua função atingindo o novo aprendizado. No caso da relação fala e escrita, isso depende da exposição ao escrito e à intervenção do outro. Nesse processo, ocorre uma flutuação entre três eixos: o da fala, o da leitura e o da escrita, até que tal aprendizado se automatize, o que implica o já citado encurtamento funcional. Vejamos situações em que ocorre tal flutuação:

\footnotetext{
18. Nem todas as letras mantêm a coincidência entre a fala do nome da letra e a fala do som da letra, como é o caso de: F (Efe); J (jota); H (Agá); L (Ele); M (Eme); N (Ene); R (Erre); S (Esse) - nas outras consoantes é menos marcada a diferença entre o som e a letra a ser escrita.
} 
LS: 30/08/2008 (2 anos de intervenção)

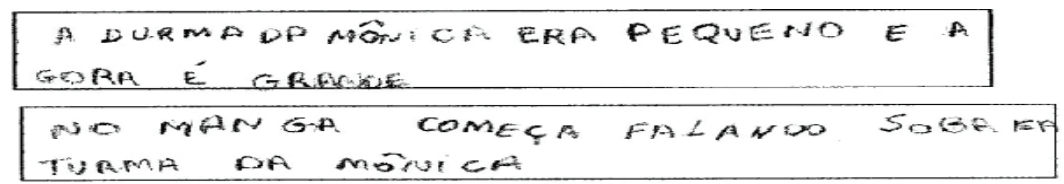

A durma da Mônica era pequeno e a gora é grande. No Mangá começa falando sobre a turma da Mônica.

LP: 30/03/2010 (8 meses de intervenção)

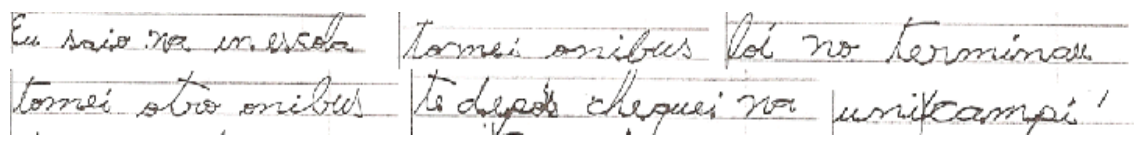

Eu saio na in escola, tomei ônibus, foi no terminau, tomei otro onibus, te depois chequei na unicampi.

CS:11/08/2011 (6 meses de intervenção)

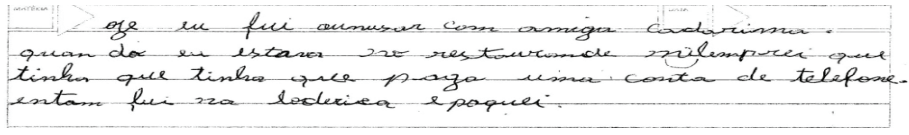

Oje eu fui aumusar com amiga Cadarina, quan do eu estava no restauramde milemprei que tinha que tinha que paga uma conta de telefone entam fui na loderica e paquei.

A flutuação entre como se fala e como se escreve ocorre com quaisquer iniciantes de escrita (porque repetem sussurrando e o traço marcado desaparece), especialmente quando não há intervenção em seus textos, como ocorre geralmente na escola. No entanto, notamos que as três crianças escreveram textos, orientadas pelo sentido, e por sua fala vernacular, distante da variedade padrão.

\section{CONCLUSÃO}

O título desse texto, Afasia e infância: registro do (in)esquecível, poderia ter a extensão registro do memorável, considerando o encontro entre criança e afásico que propusemos e que remete a caminhos comuns na linguagem (fala, leitura e escrita) e a lugares discursivos diferentes. Os afásicos "não esqueceram" "os signos" certa vez impressos "na folha" da sua psique (Heller-Roazen, 2005, p. 124). Afásicos, como os sujeitos deste texto, não controlam suas lembranças mais antigas, lembram do que deveria ser esquecido, o que interfere na estruturação do 
que falam, lêem e escrevem. A afasia funciona como um empecilho para o sujeito exercer de novo a língua: sua fala não se mantém, não é repetida por ninguém, nem por eles próprios. As crianças barradas na letra padecem da impossibilidade, às vezes temporária, de repetir e de se aproximar da língua por uma vivência incompleta da representação sonora, que não se inscreveu no corpo como memória, quando de sua entrada na língua, o que pode acontecer motivada pela inscrição da letra. Tal condição não se torna patológica, a depender da relação que se estabelece entre a criança e seu interlocutor (na família, na escola, na clínica). Por fim, propusemos o encontro com sujeitos que nos interrogam sobre a relação que mantêm com registros primitivos, antes de se tornarem sujeitos de uma língua. O caminho comum que percorrem passa pelo velho e pelo novo da língua, no processo de aprender e a reaprender.

\section{REFERÊNCIAS BIBLIOGRÁFICAS}

AGAMBEN, G. (1978). Infância e História: destruição da experiência e origem da história. Belo Horizonte: Editora UFMG, 2008.

BALIEIRO A. P. (2001). O sujeito que se estranha: manifestações de subjetividade na afasia. Mestrado, Unicamp, Campinas.

BENVENISTE, E. (1966). Problemas de Linguística Geral I. Trad. Maria da Gloria Novak e Luiza Neri, São Paulo: Editora USP, 1995.

BEHLAU, M. S.; PONTES, P. A. L. (1995). Avaliação e tratamento das disfonias. São Paulo: Lovise.

BORDIN, S. S. (2010). Fala, Leitura e Escrita: encontro entre sujeitos. Tese de Doutorado, Unicamp, Campinas.

(2008). Excesso de diagnóstico na leitura e escrita: vivências com a linguagem no CCazinho. In: Revista Estudos da Língua(gem), v.6, n.2, dez.

COUDRY, M. I. H. (1986). Diário de Narciso. Discurso e afasia: análise discursiva de interlocuções com afásicos. Tese de doutorado. Unicamp, Campinas, 1986. Publicada em livro, São Paulo: Martins Fontes, 1988.

. (1997). A lógica da linguagem patológica. In: Cadernos da F.F.C., v. 6, n. 2, p. 131-148. Marília (SP): UNESP.

. (2006). Patologia estabelecida e vivências com o escrito: o que será que dá? Texto apresentado no VII ENAL, Porto Alegre, publicado em CDrom.

(2008). Neurolingüística Discursiva: afasia como tradução. In: Estudos da Lingua(gem), Vitória da Conquista, v. 6, p. 7-36.

. (2010a). Relatório do Projeto Integrado em Neurolinguística: avaliação e bancos de dados. CNPq, 65p (impresso).

. (2010b). Caminhos da Neurolinguistica Discursiva: o velho e o novo. In: Caminhos da Neurolinguística Discursiva: teorização e práticas com a linguagem. Coudry, M. I. H.; Freire, F. M. P.; Andrade, M. L. F.; Silva, M. A. (orgs). Campinas (SP): Mercado de Letras.

COUDRY, M. I. H.; FREIRE, F. M. P. (2010). Pressupostos teórico-clínicos da Neuroliguística Discursiva. In: Caminhos da Neurolinguística Discursiva: teorização e práticas com a linguagem. Coudry, M. I. H.; Freire, F. M. P.; Andrade, M. L. F.; Silva, M. A. (orgs). Campinas (SP): Mercado de Letras. 
(adernos de EsTUDOS LINGüísTICOS (54.1) - Jan./Jun. 2012

CULIOLI, A. (1999). Pour une linguistique de l'énonciation: formalisation et opérations de repérage, v. 2. Paris: Ophrys.

DE LEMOS, C. T. (1981). Interactional Processes in the Child's Construction of Language. In: Deutsch, W. (Org.). The Child's Construction of Language. Londres: Academic Press. . (1986). A Sintaxe no espelho. In: Cadernos de Estudos Linguísticos, 10.

FRANCHI, C. (1977). Linguagem - Atividade Constitutiva. In: Caderno de Estudos Lingüísticos 22, p. 9-39, 1992.

FREUD, S. (1891) La Afasia. Buenos Aires: Nueva Visión, 1973. . (1896/1890). Carta 52. In: Publicações pré-psicanalíticas e esboços inéditos das obras completas de Sigmund Freud. Rio de Janeiro: Imago, p. 324-331, 1990. . (1901). Sobre a psicopatologia da vida cotidiana. Rio de Janeiro: Imago, 1969.

GOLDSTEIN, K. (1948). Language and language disturbances: aphasic sympton complexes and their Significance for medicine and theory of language. New York: Grune \& Stratton.

HELLER-ROAZEN, D. (2005). Ecolalias: sobre o esquecimento das línguas. Trad. Fabio A. Durão. Campinas (SP): Editora UNICAMP, 2010.

JACKSON, H.. (1874). On the nature of the duality of the brain. In: Medical Press and Circular 1: 19, 41 and 63. Reprinted in Brain 38:80-86; 87- 95; 96-103, 1915.

JAKOBSON, R.. (1941). Langage enfantin et aphasie. Paris: Flammarion, 1980. (1956) Dois aspectos da linguagem e dois tipos de afasia. In: Lingüistica e comunicação. São Paulo: Cultrix, 1975.

(1959) Aspectos Lingüísticos da tradução. In: Lingüistica e comunicação. São Paulo: Cultrix, 1975.

LURIA, A. R. (1977). Neuropsychological Studies in Aphasia. Amsterdam: Swets \& Zeitlinger B.V.

OLLER D. K.; EILERS, R.. (1988). The role of audition in infant babbling. In: Child Development, 59, p. 441- 449.

PEREIRA DE CASTRO, M. F. (2006). Língua materna e os destinos da fala infantil. Prova didática do concurso público de provimento do cargo de professora titular do Departamento de Línguística do IEL/UNICAMP.

PETITTO, L .A.; MARENTETTE, P. (1991). Babbling in the manual mode: evidence for ontogeny of language. In: SCIENCE, 251, p. 1483-1496.

RODRIGUES, N. (1989). Neurolinguística dos distúrbios da fala. São Paulo: Cortez/EDUC.

SAUSSURE, F.. (1916). Cours de Linguistique Générale. Paris: Payot, 1969.

VYGOTSKY, L. S.. (1934) Pensamento e Linguagem. Trad. Jeferson Luiz Camargo. São Paulo: Martins Fontes, 1987. 


\section{ANEXO 1}

Em nossa reflexão, a voz é entendida, desde o nascimento da criança, como a matéria prima sonora produzida na laringe pelas pregas vocais na passagem do ar vindo dos pulmões (fonte de ar), sob a ressonância do trato vocal (cavidade nasal, faríngea, pregas vocais, dentre outras estruturas), modificada pela ação dos articuladores (movimentos de língua, lábios, mandíbula, dentes e palato). O trabalho fonoaudiológico com a voz, nas disfonias ${ }^{19}$, por exemplo, tem como objetivo promover, por meio de técnicas vocais, os ajustes motores na reestruturação do padrão de fonação alterado (Behlau \& Pontes, 1995). Tais técnicas se submetem ao processo fisiológico próprio das características vocais das diferentes línguas (Jackson \& Menaldi, 1992) e, no PB, como veremos, se assentam na produção de sons realizados pelo bebê no período do balbucio. As referidas técnicas envolvem: bocejo - suspiro; estalo de língua associado a som nasal, mastigação com ressonância nasal; produção de sons nasais; produção de sons fricativos surdos e sonoros; produção do /b/ prolongado; vibração de lábios e língua $(t r, b r)$; vocalizações; entre outras. Trata-se dos mesmos sons produzidos precocemente pelo bebê por ocasião da constituição (e memória proprioceptiva) de seu próprio aparelho fonador, resultante da junção da participação funcional de órgãos dos aparelhos digestivo (ou digestório) e respiratório que passam a somar a fonação as suas primeiras funções. Por exemplo, se, no primeiro, a função da língua é participar do envio do alimento ao esôfago, no segundo, é a da produção de todos os sons; quanto ao pulmão, no primeiro, cumpre a função da manutenção da respiração e, no segundo, de manter um reservatório de ar para promover a vibração das pregas vocais.

19. Outros estudos relacionam voz e gagueira: Märtz, L. W. Alterações de voz e gagueira: problemas de linguagem? in Distúrbios da Comunicação, São Paulo, 16(2): 241-245, agosto, 2004; Carrasco, E.; Oliveira,G.; Behlau, M. Análise perceptivo-auditiva e acústica da voz de indivíduos gagos in Revista do CEFAC, vol. 12, (6),p. 179-189, 2010 